\title{
ANÁLISIS FUNCIONAL DEL UTILLAJE LAMINAR DEL NEOLÍTICO ANTIGUO DE CASTILLEJOS DE MONTEFRÍO (GRANADA)
}

\author{
USE-WEAR ANALYSIS ON THE EARLY NEOLITHIC BLADES FROM \\ CASTILLEJOS DE MONTEFRÍO (GRANADA)
}

\author{
UNAI PERALES BARRÓN* \\ JUAN F. GIBAJA BAO** \\ JOSÉ A. AFONSO MARRERO*** \\ GABRIEL MARTÍNEZ FERNÁNDEZ*** \\ JUAN ANTONIO CÁMARA SERRANO*** \\ FERNANDO MOLINA GONZÁLEZ***
}

Resumen: El asentamiento de Castillejos de Montefrío constituye un yacimiento de primer orden para poder comprender el proceso de neolitización y el desarrollo de las primeras comunidades agricultoras y pastoras a lo largo de varios milenios en el sur peninsular. Aunque son muchas las publicaciones y los proyectos de investigación que se han generado a partir de la evidencia arqueológica recogida en este asentamiento, en el presente trabajo mostramos los resultados del análisis traceológico realizado sobre conjunto significativo de láminas -fundamentalmente aquellas que sin estar retocadas presentan huellas de uso- documentado en los niveles pertenecientes cronológicamente al Neolítico Antiguo. La información obtenida de estos estudios revela la importancia de este tipo de utillaje, así como ciertos aspectos sobre las prácticas económicas de estas comunidades prehistóricas.

Palabras clave: Andalucía, Neolítico Antiguo, actividades económicas, útiles líticos, traceología.

\footnotetext{
* Dpto. de Geografía, Prehistoria y Arqueología. Universidad del País Vasco (UPV-EHU) C/Fco. Tomás y Valiente s/n, 01006 Vitoria. Correo-e: perales.unai@gmail.com

** CSIC-IMF. Departamento de Arqueología y Antropología. Investigador contratado por el Ramón y Cajal. C/Egipciaques 15, 08001 Barcelona. Correo-e: jfgibaja@imf.csic.es
}

Abstract: Castillejos de Montefrío (Granada) is an openair site located on the South of the Iberian Peninsula. This settlement is one of the most important sites to understand the neolithization process and the development of first farming societies for several millennia. In this paper we present the results of the use-wear analyses made on a selection of the flint blades (most of them without retouch) from the Early Neolithic levels. Our purpose, through the Traceology, is to recognize some activities developed in the settlement and provide some information about the site function. The results obtained show the importance of this kind of tools and reveal some economical aspects of the first farmers communities settled down in this region.

Key words: Andalusia, Early Neolithic, economic activities, lithic tools, use-wear analysis.

\footnotetext{
*** Departamento de Prehistoria y Arqueología de la Universi-
} dad de Granada. Facultad de Filosofía y Letras, Campus de Cartuja s/n, 18071 Granada. Correo-e: jaamarre@ugr.es, gabmar@ugr.es, jacamara@ugr.es,molinag@ugr.es 


\section{INTRODUCCIÓN: OBJETIVOS DEL TRABAJO}

El asentamiento de Castillejos de Montefrío fue ocupado por las primeras comunidades neolíticas del sur peninsular hacia mediados del VI milenio cal a.C. Mediante el desarrollo de diversos proyectos de investigación se han podido reconocer más profundamente las características tecno-tipológicas y funcionales del utillaje lítico tallado perteneciente a estas comunidades agricultoras y ganaderas. El objetivo de este trabajo es, por tanto, evaluar a través de los estudios traceológicos la funcionalidad de los útiles de piedra y su inserción en las actividades de subsistencia de estos grupos humanos. La propia entidad cronoestratigráfica y la amplia muestra de materiales arqueológicos recuperados en este yacimiento hacen que toda la información generada a partir de su estudio tenga siempre una importante trascendencia para el conocimiento de aquellas primeras sociedades productoras.

En el presente trabajo hemos dirigido nuestra atención sobre la función de las láminas de sílex del Neolítico Antiguo, ya que están ampliamente representadas en este yacimiento. Aunque se distinguieron 6 niveles pertenecientes a este momento cronológico, nosotros presentamos las piezas seleccionadas de manera global porque, como vamos a ver, se insertan en un momento muy preciso entre el 5400-5000 a.C., y porque no se aprecian diferencias significativas a nivel de materias primas, tecnología y morfología. En definitiva, a través de este trabajo pretendemos:

a) Valorar la importancia que representó el utillaje laminar sin retoque en la estructura económica y social de los grupos prehistóricos, en general, y de los neolíticos, en particular. Es sabido que esta clase de piezas quedan excluidas de los sistemas tipológicos tradicionales basados en la morfotecnología de los artefactos retocados.

b) Conocer el modo en que fueron usados estos útiles y aportar información que ayude a comprender el papel que desempeñaba el retoque en aquellos que lo tienen.

c) Identificar las actividades productivas a las que fueron destinados.

d) Contribuir al conocimiento de algunos procesos productivos y prácticas económicas desarrolladas por las comunidades humanas que habitaron este asentamiento entre 5400-5000 cal a.C.

No obstante, cabe señalar el carácter parcial de los resultados que vamos a exponer, en tanto que no hemos estudiado la totalidad del utillaje laminar, sino una amplia muestra. En todo caso, consideramos que este nutrido conjunto de láminas nos aproximan, en gran medida, a las actividades desarrolladas con este tipo de instrumentos.

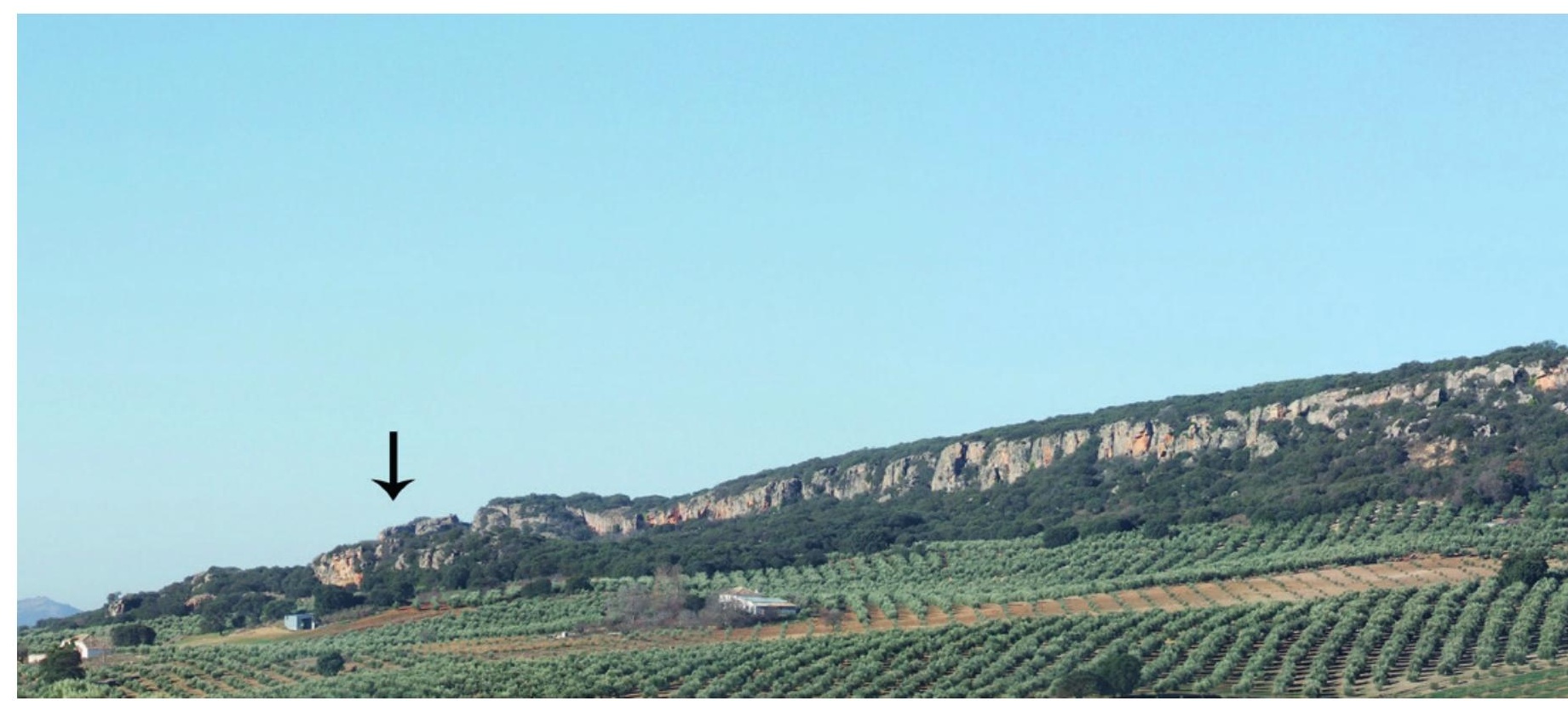


aunque con un hiato entre 4900/4800 y 4300/4200 cal a.C. en la zona excavada (Martínez et al. 2009, Martínez et al. 2010).

La mayor parte de las fechas hasta ahora obtenidas corresponden a los primeros niveles de ocupación del yacimiento, los periodos I y II, situados en conjunto entre 5400 y 4800 cal a.C., de manera que se ha estimado que las seis primeras fases estratigráficas correspondientes a momentos avanzados del Neolítico Antiguo podrían haberse desarrollado entre 5400 y 5100/5050 cal a.C. (Martínez et al. 2010).

La importancia de Los Castillejos es aún mayor si tenemos en cuenta que no solo es uno de los pocos yacimientos al aire libre del Neolítico Antiguo de Andalucía Oriental, sino que además es el único que permite realizar el seguimiento pormenorizado de una superposición estratigráfica de entidad. Es más, de los escasos yacimientos al aire libre de tales fechas excavados en las áreas cercanas de la península ibérica (Ramos y Lazarich 2002; Fernández et al. 2006; Esquembre et al. 2008; García Puchol et al. 2008; Vijande 2009; Díez et al. 2010; Torregrosa et al. 2011; Cortés et al. 2012), ninguno presenta tal característica y todos comparten, en general, la presencia de diversos tipos de fosas y evidencias aisladas de ocupación, aunque existan también algunas estructuras monumentales de delimitación como en el caso de Mas d'Is (Penàguila, Alicante) (Bernabeu et al. 2006).

Se han adscrito las fases estratigráficas 1 a 6 de la ocupación de Los Castillejos al Neolítico Antiguo Avanzado, con una duración estimada de 5311 a 5002 cal a.C., a partir de la combinación de las dataciones de radiocarbono disponibles calibradas a $1 \sigma$ mediante el programa "Calib 6.1.1". Entre estas fases y las siguientes (7 a 11), consideradas del Neolítico Medio Inicial (entre el 5080 y el 4936 cal a.C. al 74,56\% de probabilidad dentro del rango de $1 \sigma$, según la combinación de las dataciones), no existe ningún hiato, aunque se han documentado determinados cambios, tanto en los materiales cerámicos como en las estructuras de combustión, que justifican tal diferenciación (Cámara et al. 2005). Estas últimas se realizaron en el segundo periodo solo con barro. Eran menos numerosas y contenían un relleno de ceniza clara resultado de una combustión continua y completa. Respecto a los materiales, las piezas cerámicas de las fases del Neolítico Antiguo Avanzado están más fragmentadas y algunas presentan decoración cardial o a peine, mientras que otras tienen una combinación de impresión e incisión que ha recibido el nombre de "boquique" y "falso boquique" (Alday et al. 2011). Se trata de una asociación de técnicas decorativas que se ha querido recientemente atribuir a las fases más antiguas del Neolítico (Bernabeu et al. 2009), aunque no ha sido documentada en los casos argüidos para defender en Andalucía la existencia de un horizonte precardial. Aquí se comprueba, en cualquier caso, su presencia en las fases recientes del Neolítico Antiguo, como confirman las dataciones radiocarbónicas. Este tipo de decoraciones van desapareciendo a la vez que adquieren más importancia las guirnaldas realizadas con incisión, los baños con almagra y las aplicaciones plásticas que serán más abundantes en el periodo siguiente o Neolítico Medio Inicial. En el plano técnico también hay cambios en la cerámica con una adición de desgrasantes más consistente a medida que transcurre el tiempo.

En cuanto al uso del espacio, durante el Neolítico Antiguo Avanzado esta zona del asentamiento acogió una serie de grandes hogares dedicados principalmente al tostado de la variedad de cereales que se cultivaban en el entorno (Rovira 2007). Hemos deducido que quienes trabajaban en estas estructuras aprovechaban el calor generado por las mismas para el tratamiento térmico de la materia prima (prenúcleos) para la producción de artefactos de piedra tallada.

\section{RASGOS TÉCNOLÓGICOS GENERALES DE LA INDUSTRIA DE PIEDRA TALLADA DEL NEOLÍTICO ANTIGUO AVANZADO DE LOS CASTILLEJOS DE MONTEFRÍO}

Los resultados del análisis de la industria de piedra tallada de las fases del Neolítico Antiguo de Los Castillejos han sido publicados recientemente y se resumen a continuación (Martínez et al. 2010:164-166).

El conjunto está integrado por cerca de 2.500 piezas de las que 1.842 pertenecen a las siguientes categorías técnicas de la siguiente manera: $2(0,1 \%)$ percutores, 34 (1,8\%) núcleos, $631(34,3 \%)$ lascas, 702 (38,1\%) láminas, $420(22,8 \%)$ esquirlas y $53(2,9 \%)$ indeterminables (fig. 2). Interesa resaltar la importancia que en este conjunto alcanzan las láminas prismáticas con un número de 605 ejemplares, lo que representa el 32,8\% de los artefactos. Un aspecto especialmente relevante de este conjunto de piedra tallada ha sido la constatación de la práctica habitual del tratamiento térmico en el proceso de talla de las láminas prismáticas. Aquel se ha reconocido en 346 piezas (18,8\% de los artefactos), de las que 327 son láminas $(46,6 \%)$ y 16 núcleos para la talla de láminas $(80 \%)$.

El análisis tipológico se ha realizado de acuerdo con la lista compuesta por catorce grupos tipológicos 


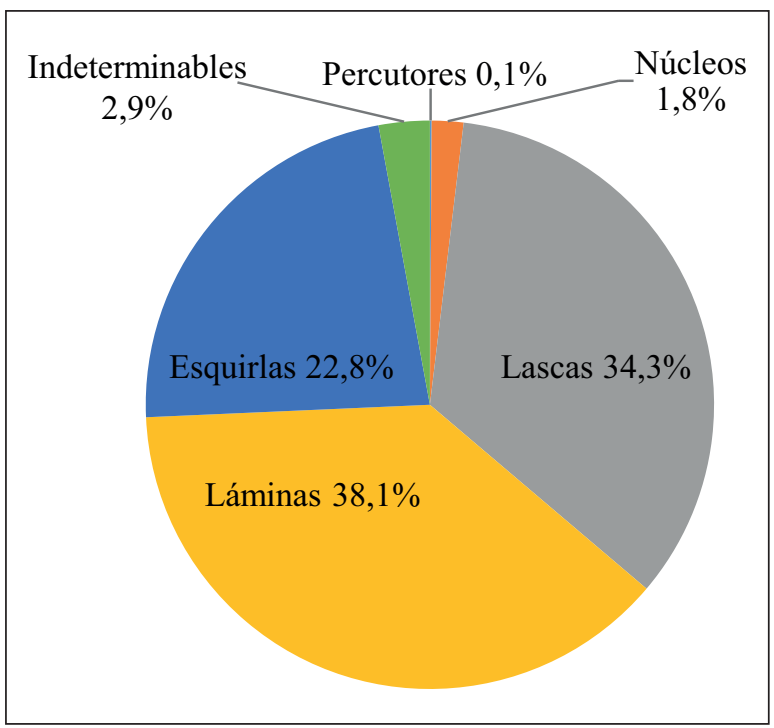

Figura 2. Gráficos de porcentajes de la clasificación de las industrias de piedra tallada de Los Castillejos de Montefrio (fases 1 a 6 del Neolítico Antiguo Avanzado).

elaborada para la piedra tallada de la Prehistoria Reciente de la Alta Andalucía y el sureste de la península ibérica
(Martínez 1985; Afonso 1993; Martínez y Afonso 2008). Los $115(6,2 \%)$ artefactos clasificados como útiles se distribuyen según se presenta en la figura 3.

El análisis de las materias primas nos ha permitido concluir que proceden mayoritariamente de los depósitos jurásicos del Subbético Medio localizados en las proximidades del yacimiento. La variabilidad de recursos líticos de la zona está representada en la industria analizada, sin que por el momento se pueda afirmar una procedencia exclusiva. Entre los distintos afloramientos reconocidos, destaca la fuente de materia prima de Los Gallumbares (Martínez et al. 2006: 300-301) a la que habría que añadir la recientemente reconocida en el paraje "Cortijo del Perú" y publicada como "Cerro del Reloj" (Morgado et al. 2001: 145). En razón del número de evidencias relacionadas con la producción lítica se podría suponer que ambas fuentes han sido potencialmente los puntos de obtención de materia prima de rocas silíceas de Los Castillejos. No obstante, tiene que tomarse en consideración que también se han reconocido otras más cercanas al asentamiento (Morgado et al. 2001: 80), si bien en ellas los testimonios de producción laminar neolítica son menos abundante.

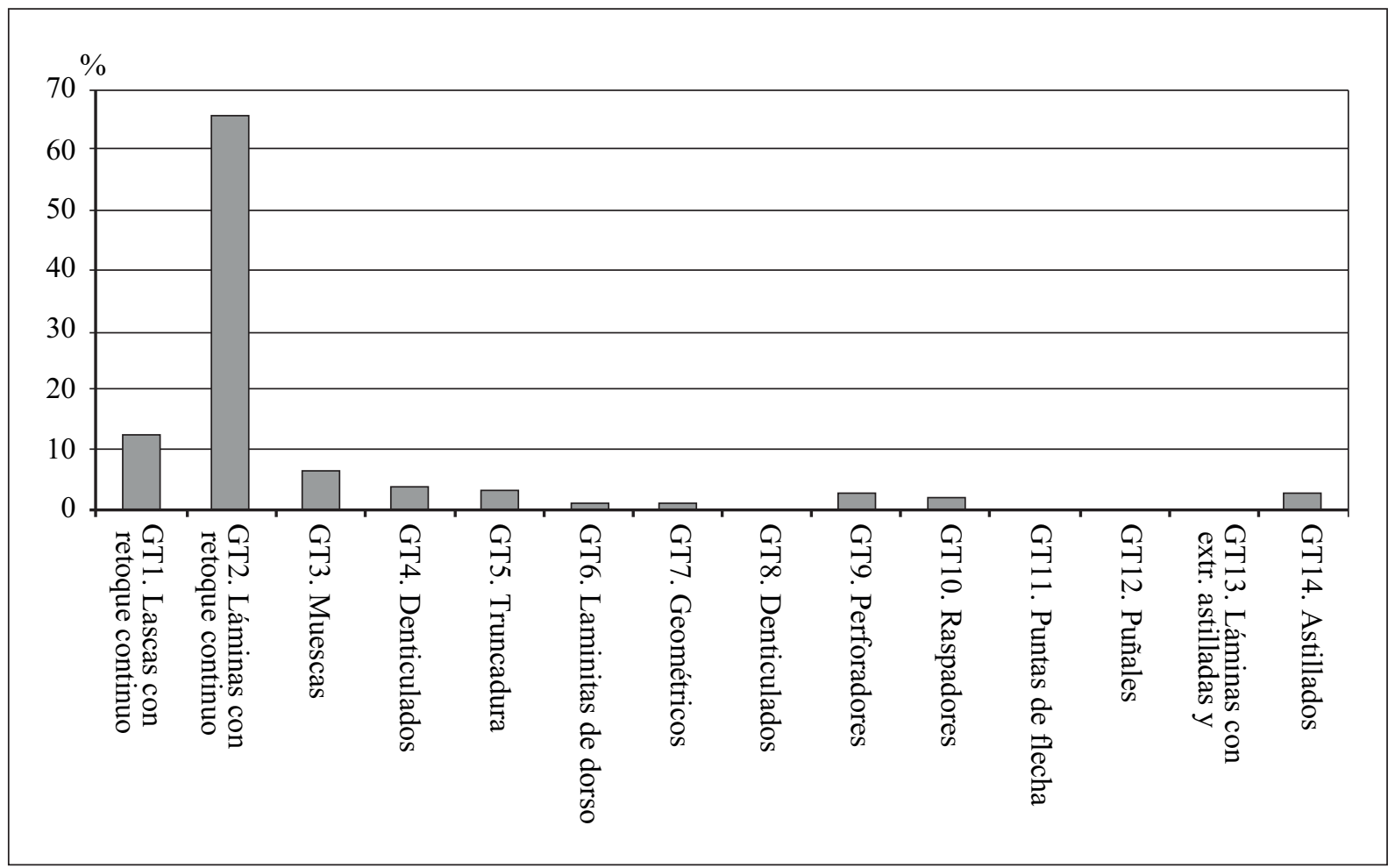

Figura 3. Porcentajes de la clasificación de los útiles retocados del Neolítico Antiguo de Los Castillejos de Montefrio por grupos tipológicos (Fases 1 a 6 Neolítico Antiguo Avanzado). 
En resumen, y a la espera de un tratamiento más exhaustivo de la materia prima, entendemos que la población de Los Castillejos practicó un aprovisionamiento directo en los afloramientos de sílex cercanos, aunque parece que prefirió aquellos que aun estando algo más lejanos permitían conseguir una materia más abundante y de mejor calidad. La preparación preliminar y la explotación de los núcleos para la producción de láminas prismáticas se llevó a cabo tanto en la propia fuente de materia prima, como en el asentamiento. Mientras que se ha constatado el tratamiento térmico de estos núcleos en el asentamiento, no es posible afirmarlo por el momento para las áreas fuentes de materia prima.

La aplicación del tratamiento térmico a los núcleos previo a la talla de los mismos genera una fenomenología que, en la mayoría de los casos, puede ser reconocida macroscópicamente (Afonso 1993; Domanski y Web 2007; McCutcheon y Kuehner 1997). En la industria del Neolítico Antiguo de Los Castillejos se han identificado piezas (tanto láminas como núcleos) con tratamiento térmico que pertenecen a todas las unidades sedimentarias adscritas a dicho periodo (tabla 1), por lo que se puede concluir que el inicio de la aplicación de esta técnica en la producción laminar puede datarse, al menos, desde 5400 a.C. Además, este procedimiento técnico parece estar relacionado con la aplicación de la presión como técnica de talla de los mismos, como parece inferirse de los estudios experimentales y morfotécnicos (Martínez et al. 2010: 165-166).

Tabla 1. Cantidad y porcentajes de láminas y núcleos con tratamiento térmico de las fases 1 a 6 del Neolítico

Antiguo de Los Castillejos de Montefrio.

\begin{tabular}{|c|c|r|c|c|}
\hline \multirow{2}{*}{ Fase } & \multicolumn{2}{|c|}{ Láminas } & \multicolumn{2}{c|}{ Núcleos } \\
\cline { 2 - 5 } & $\mathrm{n}^{\text {o }}$ & \multicolumn{1}{c|}{$\%$} & $\mathrm{n}^{\text {o }}$ & $\%$ \\
\hline 1 & 42 & 12,1 & 2 & 0,6 \\
\hline 2 & 24 & 6,9 & 2 & 0,6 \\
\hline 3 & 36 & 10,4 & - & - \\
\hline 4 & 140 & 40,5 & 10 & 2,9 \\
\hline 5 & 59 & 17,0 & - & - \\
\hline 6 & 26 & 7,5 & 2 & 0,6 \\
\hline
\end{tabular}

El análisis tecno-tipológico nos permite sintetizar los rasgos generales de la producción lítica tallada del Neolítico Antiguo y Medio de Andalucía. Los grupos neolíticos parecen no haber tenido restricciones al acceso a la materia prima, con independencia de la mayor o menor distancia de su lugar de asentamiento con respecto a los afloramientos de sílex. Desde estos se ha transportado bien materia prima para soporte de los núcleos, bien prenúcleos o núcleos en las fases iniciales de su explotación y productos de talla. A tenor de la información obtenida en Los Castillejos, parece que en los poblados existían áreas funcionalmente diferenciadas donde se tallaban núcleos para lascas o se preconformaban núcleos para láminas y otras donde se procedía al tratamiento térmico de los prenúcleos para láminas. Las poblaciones neolíticas usaron los artefactos de piedra tallada en casi todos los ámbitos de desarrollo de sus actividades económicas; incluso las personas que tallaban llevaban consigo núcleos de láminas que tallaban cuando les surgía la necesidad de obtener un producto laminar para destinarlo a una actividad determinada. No hay indicios que permitan afirmar la existencia de especialistas en la talla; es más, podría sugerirse que la talla era practicada sin discriminación.

Esta tecnología generaba principalmente soportes laminares que eran empleados en una gran variedad de funciones. Aparte de estos, puede citarse un reducido elenco de útiles con alta modificación secundaria como geométricos, algunos perforadores sobre láminas, así como denticulados, raspadores espesos y astillados realizados sobre lascas (fig. 3).

\section{EL ANÁLISIS FUNCIONAL DE LOS INSTRUMENTOS LAMINARES}

\subsection{Caracterización y estado de conservación del utillaje laminar estudiado}

El análisis traceológico que hemos realizado se ha llevado a cabo siguiendo las pautas metodológicas establecidas por distintos autores y detalladas en diversos trabajos (González e Ibáñez 1994; Gassin 1996; Gibaja 2003). El estudio ha sido llevado a cabo mediante la observación macroscópica y microscópica del material, para lo cual hemos utilizado una Lupa binocular Leica MZ16A y un microscopio metalográfico Olympus BH2 de entre 50X-400X aumentos dotado con una cámara Canon 450D. Además, hemos empleado un software fotográfico que permite adquirir una batería de imágenes para al final reconstruir una totalmente enfocada (Helicon Focus v. 4.62).

Para este estudio, hemos seleccionado aquellos soportes laminares, en la mayoría de los casos sin retoque, que tenían filos potencialmente utilizables. En muchos casos se apreciaban incluso modificaciones macroscópicas, 
resultado probablemente de su utilización. Ampliando la perspectiva hacia a otros yacimientos neolíticos (caso por ejemplo de La Vaquera, Cova de l'Or, Atxoste, Murciélagos de Zuheros, etc), parece que las láminas son útiles polivalentes que suelen presentar huellas de uso vinculadas con una amplia gama de materias trabajadas. Partíamos entonces de que si eso fuera así, para el caso de Castillejos de Montefrio, el estudio de las láminas nos permitiría obtener información relevante sobre las actividades realizadas en el yacimiento.

Hemos analizado un total de 164 útiles sobre soporte laminar, de los cuales $106(64,2 \%)$ presentan huellas de uso. De todos ellos 75 están sin retocar y 31 retocadas: 24 muestran un retoque lateral continuo, 3 tienen muescas, otro está configurado como un raspador, 2 presentan un retoque de apariencia a modo de buril y 1 tiene una truncadura. Así, 31 (81,6\%) de las 38 piezas retocadas y $75(59,5 \%)$ de las 126 sin retoque muestran huellas de uso. Estos datos, y la revisión general que hicimos del material en el momento de la selección, indican la importancia de los productos sin retoque -en este caso de las láminas- en el utillaje lítico empleado.

Por otra parte, en 3 láminas sin retoque $(1,8 \%)$ no hemos detectado estigmas de utilización, 8 piezas (7 láminas sin retoque y un denticulado sobre lámina que suman un 4,9\%) las hemos catalogado como "no analizables" debido a las fuertes alteraciones que han sufrido, y en 47 casos (41 láminas sin retoque, 5 láminas con retoque lateral continuo y un perforador sobre lámina, que representan el 28,6\% de los soportes analizados) no tenemos criterios sólidos para definir si fueron o no usadas. Estas últimas son piezas que suelen tener pequeñas melladuras y ligeros pulidos que pudieron generarse por el trabajo de una materia blanda pero también por alteraciones ante y postdeposicionales.

Para presentar los datos, vamos a valorar primeramente los aspectos morfológicos y la función a la que se destinó cada tipo de útil para, finalmente, aportar una visión de conjunto que englobe las actividades reconocidas (fig. 4).

En relación a la materia prima hemos observado que la mayoría de los útiles $(90,8 \%)$ se elaboraron con sílex de excelente calidad, predominantemente de coloración gris pardo, siendo anecdótica la presencia de una lámina realizada sobre sílex negro.

El estado de conservación del conjunto analizado sesga, en ocasiones, la obtención de algunos datos. Así, por ejemplo, la mayoría de las láminas aparecen fracturadas (80\%); solamente 21 láminas (3 de ellas con retoque lateral y un raspador) se conservan completas. Aunque ello nos ha impedido conocer íntegramente las

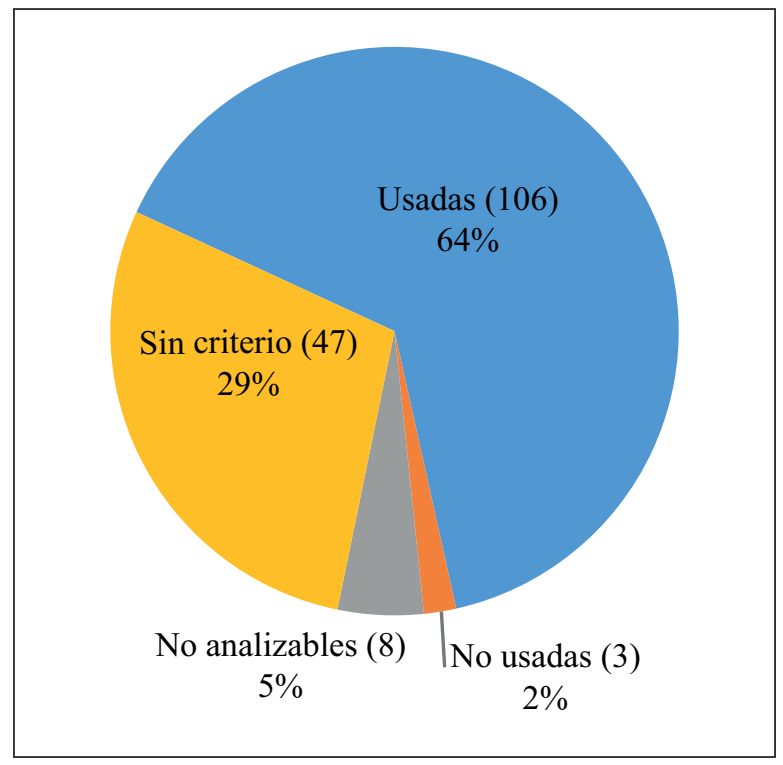

Figura 4. Diagnóstico funcional del utillaje laminar analizado.

dimensiones de este conjunto de útiles, las piezas completas nos han orientado sobre la posible dimensión del utillaje laminar que fue elaborado.

Por otro lado, las superficies de las piezas han sufrido un conjunto de alteraciones, entre las que sobresale especialmente la alteración térmica (que puede estar ligada tanto a acciones tecnológicas como a fenómenos postdeposicionales). Dicha alteración ha generado habitualmente un intenso lustre que nos ha dificultado en muchas ocasiones hacer una determinación precisa de la materia trabajada y/o del movimiento efectuado. Este lustre afecta sobre todo a la observación de los micropulidos generados por las materias blandas de origen animal, como la carne, el pescado o la piel fresca, ya que quedan enmascarados por el brillo del mismo. Esta circunstancia explica el elevado número de piezas que hemos catalogado como usadas sobre una materia "indeterminada".

El análisis tipométrico del conjunto laminar muestra que se buscan soportes con una anchura y un espesor similares (de entre 11-13 mm de anchura y 2-4 mm de espesor). La norma la rompen el raspador (realizado sobre una lámina mucho más ancha y espesa) y las dos piezas usadas a modo de buril, que son algo más anchas y espesas (fig. 5). Las 21 piezas completas muestran una longitud media de $37,2 \mathrm{~mm}$; no habiéndose detectado, sin embargo, indicadores de una fractura intencionada (para la búsqueda de un tamaño concreto), ya que la media de las piezas fracturadas es $10 \mathrm{~mm}$ menor $(26,7 \mathrm{~mm})$, y tampoco puede relacionarse de manera fiable la rotura de las mismas con el uso. 


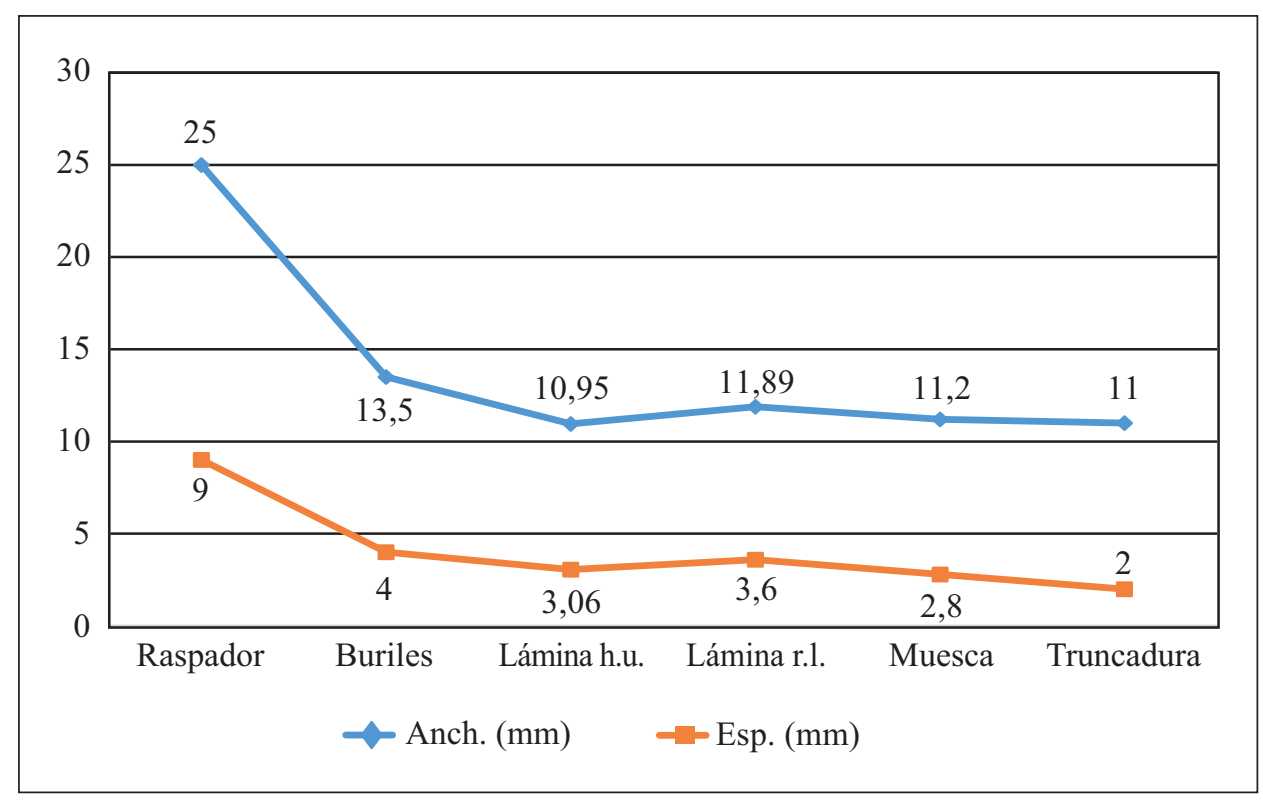

Figura 5. Dimensiones medias (Anchura/ Espesor) de los útiles laminares estudiados.

\subsection{Los usos identificados}

En las 106 piezas con uso hemos identificado un total de 152 zonas activas empleadas mayoritariamente en el trabajo de distintas materias animales y vegetales (fig. 6). Este dato evidencia que muchas de las láminas eran utilizadas por ambos laterales, aprovechando muchas veces los filos naturales (fig. 7). Además, puede observarse cómo la aplicación del retoque influye en el tipo de acción y la materia trabajada. Así, mientras que las láminas en bruto se han destinado principalmente a las actividades de carnicería y el trabajo de la piel (figs. 8 y 9), las materias de mayor dureza (hueso/asta) y algunos vegetales se han manipulado principalmente con los

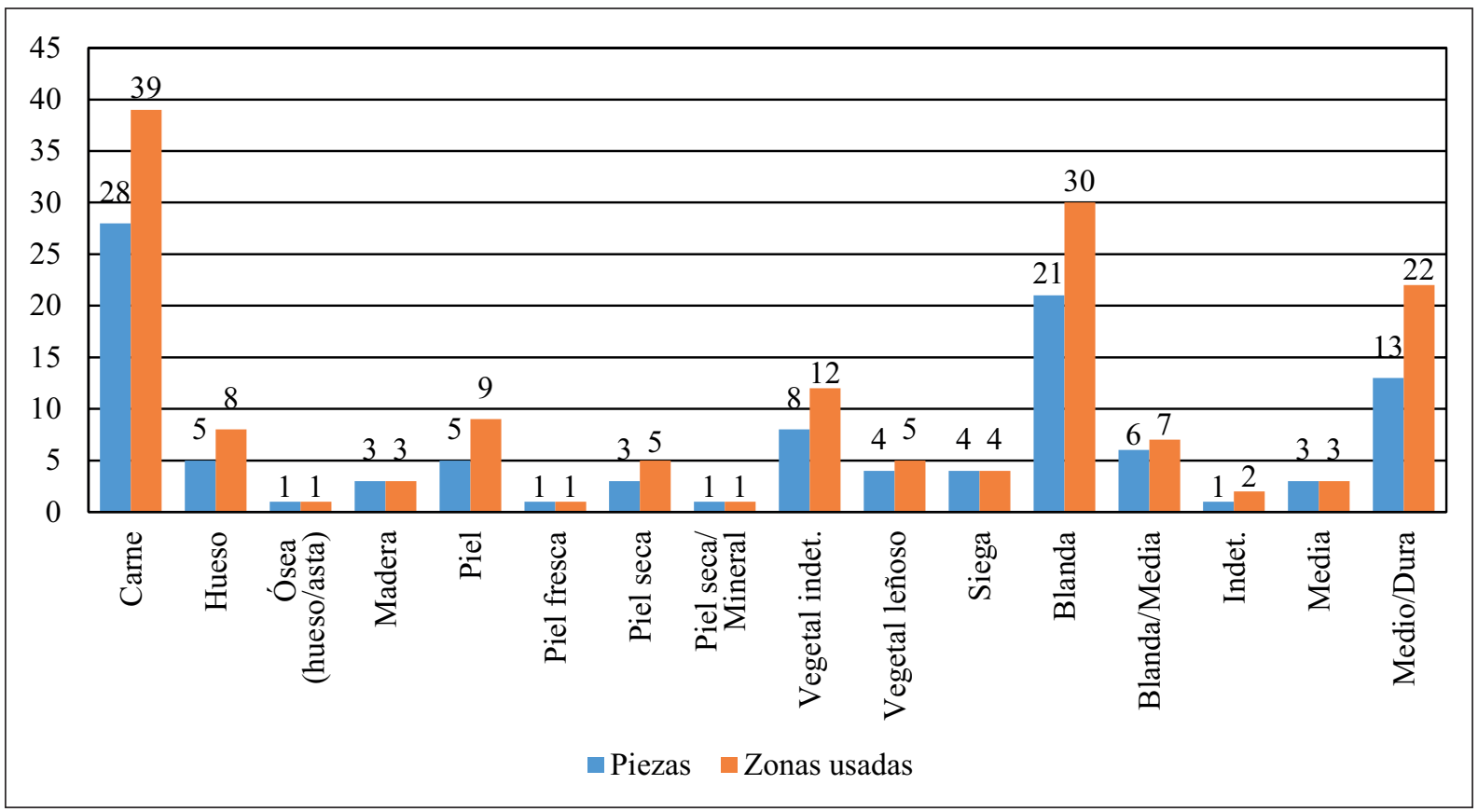

Figura 6. Gráfico en el que se refleja la cantidad de piezas usadas sobre cada materia y el número de zonas usadas en global (hay que tener en cuenta que existen piezas con más de una zona usada). 


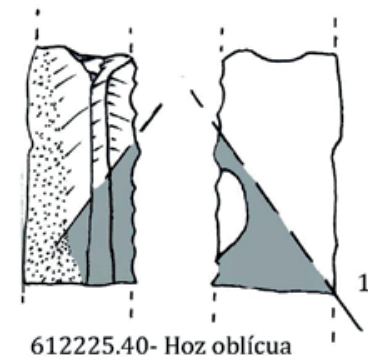

612225.40- Hoz oblícua

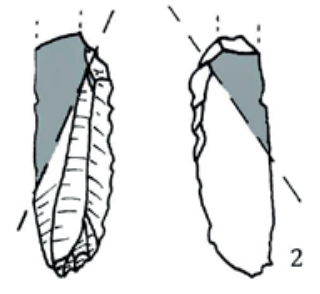

6127715- Hoz oblícua

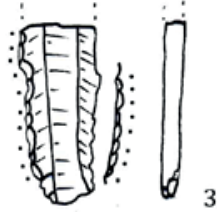

614238.10- R. Piel

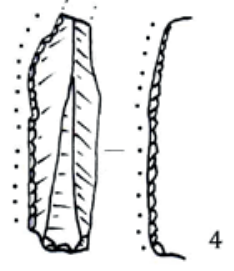

613444.10- R. hueso/asta

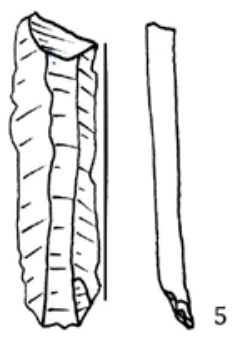

612373.11

C. Blanda

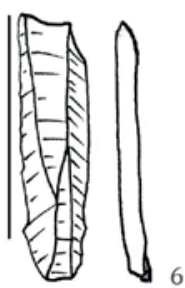

613444.5

Carnicería

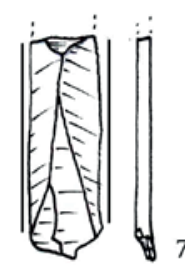

612728.4

Carnicería

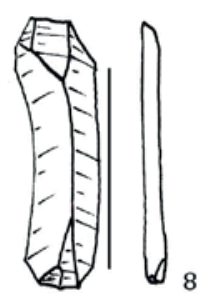

612069.3

C. Blanda

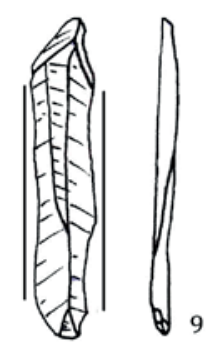

613606.1

Carnicería

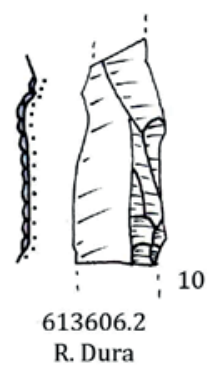

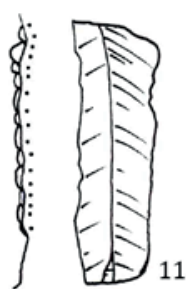

613639.3

R. hueso/asta

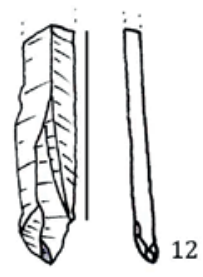

613639.2

Carnicería

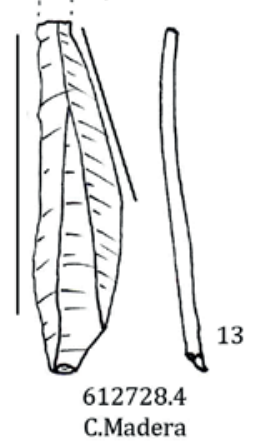

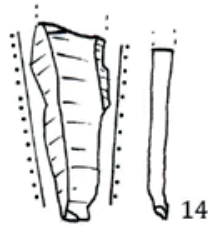

612728.2 R./C. Piel Seca
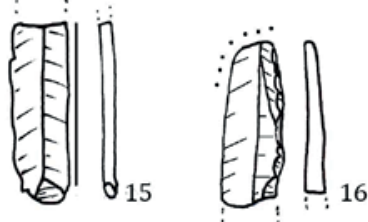

612841.8 Carnicería

613606.3 R. Vegetal

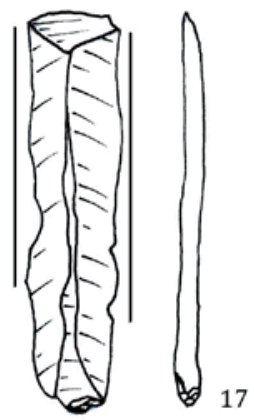

613633.1

C. Blanda

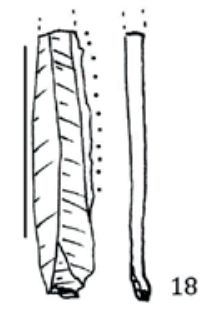

612373.5

Carnicería + R. Piel

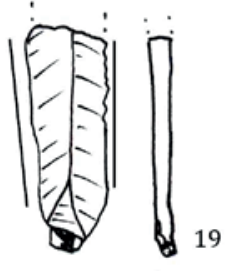

612373.22

C. Blanda

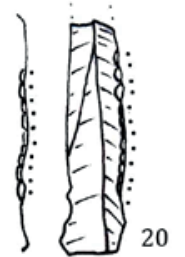

612096.8

R. Madera

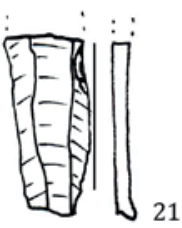

613013.16 C Piel seca

Figura 7. Algunas de las láminas analizadas pertenecientes al Neolítico antiguo de Castillejos de Montefrío. Se detalla la materia y la acción (línea continua = corte// línea discontinua = raspado) en todas ellas. Se indica además en las dos primeras (hoces) la posición oblicua con respecto al enmangue. 


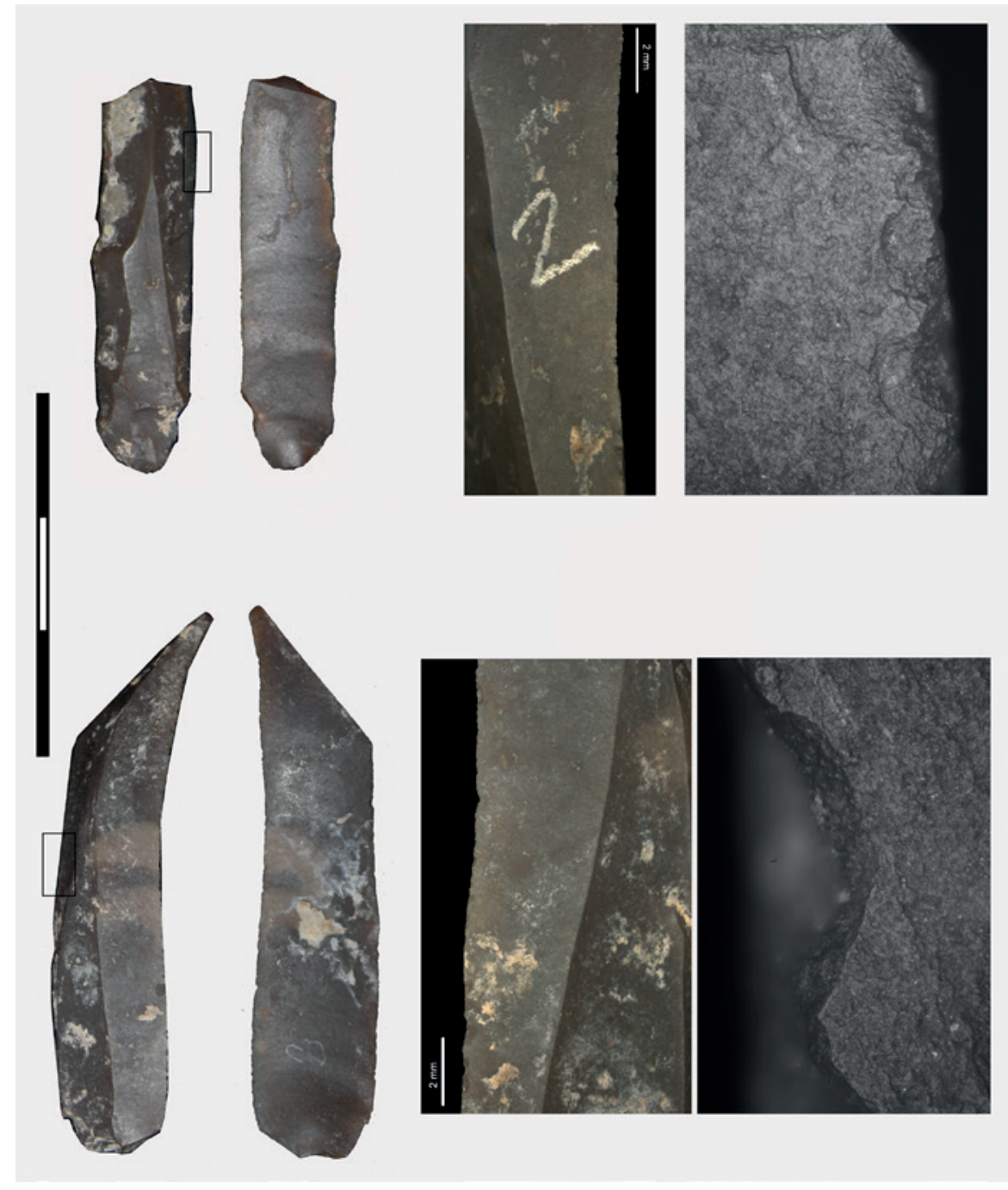

Figura 8. Láminas empleadas en actividades de descarnado. Las fotos microscópicas están a 200X. filos retocados mediante acciones casi siempre de raspado. Es decir, se advierte una estrecha relación entre el ángulo del filo activo, la función (acción) y la materia trabajada que, en última instancia, también se vincula con las dimensiones de los productos laminares: mientras que las piezas menos espesas (que presentan ángulos de filo más cortantes) son usadas en bruto mediante movimientos longitudinales, las de mayor espesor se encuentran normalmente retocadas en sus laterales y se utilizan mediante acciones transversales. Tal y como muestra la figura 5, existe una diferencia de $1 \mathrm{~mm}$ en las medias entre unas y otras láminas. Todo ello implica una gestión perfectamente estructurada de los soportes laminares en relación al utillaje y a los usos del mismo.

A pesar de las tendencias generales apuntadas, las herramientas estudiadas no se han diseñado para restringirse a trabajos concretos, sino que han estado implicadas en la manipulación de diversas materias mediante distintos tipos de acciones (tabla 2). Por ejemplo, con las láminas en bruto también se han raspado vegetales leñosos y pieles y con las de retoque continuo lateral se han trabajado materias óseas y se han segado cereales. Con todo, la importancia de las alteraciones nos ha impedido realizar una lectura más detallada y precisa de los datos obtenidos.

\subsection{Descripción de la zona activa}

Además de conocer el tipo de materias manipuladas por los útiles laminares, hemos analizado el tipo de zona activa empleada, ya que, si bien hemos tratado con un conjunto relativamente homogéneo, existen diferencias internas relacionadas con el diseño de 


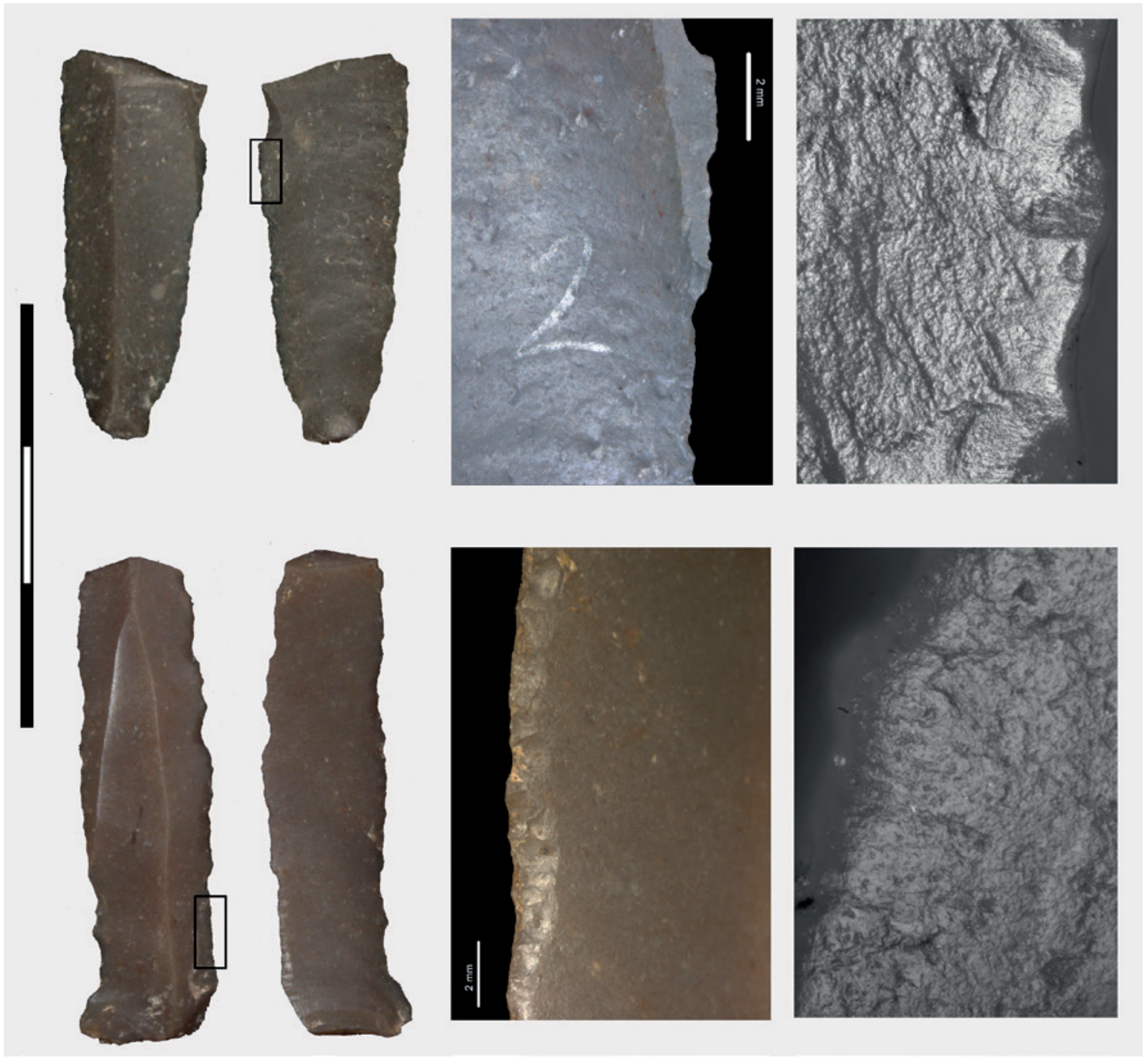

Figura 9. Láminas utilizadas para el raspado de pieles secas. Las fotos microscópicas están a 200X.

las distintas zonas activas que presentan en ocasiones usos diferentes.

Así, hemos constatado que se seleccionaron especialmente aquellas láminas que presentan filos de morfología rectilínea y, esporádicamente, convexos y cóncavos. Hemos comprobado que el índice de utilización (ratio entre el número de zonas activas identificadas y el número de piezas estudiadas) ha sido similar en todos los soportes laminares, apreciándose que en muchas de ellas existían dos (y hasta tres) zonas activas (tabla 3). Ello indica un aprovechamiento bastante intensivo de este tipo de utillaje. Finalmente, hemos confirmado que los ángulos de los filos activos han sido, lógicamente, más altos en aquellas piezas retocadas, que además se han empleado preferentemente en acciones transversales (ligadas sobre todo con el trabajo de materias duras y abrasivas como la piel y el hueso). Contrariamente los filos agudos se han utilizado asiduamente para actividades de corte sobre materias más blandas (carnicería, vegetales...) (fig. 10). Los datos obtenidos muestran una tendencia a retocar los soportes más espesos. Así, mientras que la mayoría de las zonas activas usadas sin retoque se asocian a láminas de entre 2-4 mm de espesor (siendo muy frecuentes las de 2 y $3 \mathrm{~mm}$ ), el retoque se aplica a los filos de las láminas con un espesor igual o mayor a $4 \mathrm{~mm}$ (siendo el grupo más numeroso aquellas de entre $4-5 \mathrm{~mm}$, llegando a retocarse láminas de hasta $10 \mathrm{~mm}$ de espesor como el raspador de grandes dimensiones). Como consecuencia, las zonas activas con mayor ángulo de filo se corresponden normalmente a piezas más espesas que presentan retoque. 
Tabla 2. Se reflejan los tipos de soportes utilizados en cada materia y el movimiento de trabajo empleado.

\begin{tabular}{|c|c|c|c|c|c|c|c|c|}
\hline \multirow{2}{*}{\multicolumn{3}{|c|}{ PIEZAS LAMINARES }} & \multicolumn{6}{|c|}{ GRUPO TIPOLÓGICO } \\
\hline & & & \multirow{2}{*}{$\begin{array}{c}\text { Lámina sin } \\
\text { retoque }\end{array}$} & \multirow{2}{*}{$\begin{array}{l}\begin{array}{l}\text { Lámina retoque } \\
\text { lateral continuo }\end{array} \\
3\end{array}$} & \multirow[t]{2}{*}{ Muesca } & \multirow[t]{2}{*}{ Truncadura } & \multirow[t]{2}{*}{ Raspador } & \multirow{2}{*}{$\begin{array}{r}\text { TOTAL } \\
39\end{array}$} \\
\hline \multirow{28}{*}{ 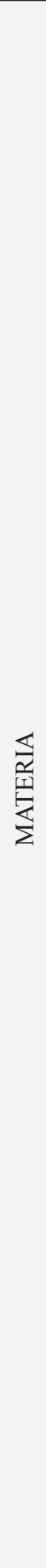 } & Carnicería & Cortar & & & & & & \\
\hline & \multirow{3}{*}{ Hueso } & Cortar & & 1 & & & & 1 \\
\hline & & Raspar & & 4 & 2 & & & 6 \\
\hline & & Ranurar & 1 & & & & & 1 \\
\hline & Ósea: hueso/asta & Raspar & & 1 & & & & 1 \\
\hline & Madera & Raspar & 3 & & & & & 3 \\
\hline & \multirow{2}{*}{ Piel } & Cortar & 4 & & & & & 4 \\
\hline & & Raspar & 3 & 2 & & & & 5 \\
\hline & Piel fresca & Raspar & & 1 & & & & 1 \\
\hline & \multirow{3}{*}{ Piel seca } & Cortar & 2 & & & & & 2 \\
\hline & & Raspar & 1 & 1 & & & & 2 \\
\hline & & Mixto & 1 & & & & & 1 \\
\hline & Piel seca/Miner. & Raspar & 1 & & & & & 1 \\
\hline & \multirow{2}{*}{ Vegetal indeterm. } & Cortar & 6 & & & & & 6 \\
\hline & & Raspar & 2 & 4 & & & & 6 \\
\hline & Vegetal leñoso & Raspar & 2 & 3 & & & & 5 \\
\hline & Cereal (siega) & Cortar & 2 & 2 & & & & 4 \\
\hline & Indeterm. & Raspar & 2 & & & & & 2 \\
\hline & \multirow{2}{*}{ Blanda } & Cortar & 27 & 1 & 1 & 1 & & 30 \\
\hline & & Raspar & & & & & & \\
\hline & \multirow{2}{*}{ Blanda-Media } & Cortar & 6 & & & & & 6 \\
\hline & & Raspar & & 1 & & & & 1 \\
\hline & \multirow{2}{*}{ Media } & Cortar & & & & & & \\
\hline & & Raspar & 2 & 1 & & & & 3 \\
\hline & \multirow{3}{*}{ Media-Dura } & Cortar & 2 & & & & & 2 \\
\hline & & Raspar & 6 & 11 & 2 & & & 19 \\
\hline & & Mixto & & & & & 1 & 1 \\
\hline & \multicolumn{2}{|c|}{ TOTAL } & 109 & 36 & 5 & 1 & 1 & 152 \\
\hline
\end{tabular}


Tabla 3. Índice de utilización de los útiles laminares.

\begin{tabular}{|l|c|c|c|}
\hline \multicolumn{1}{|c|}{ Tipo } & $\mathrm{N}^{\text {o piezas }}$ & $\mathrm{N}^{\text {o }}$ Z.A. & $\begin{array}{c}\text { Índice } \\
\text { utilización }\end{array}$ \\
\hline $\begin{array}{l}\text { Lámina sin } \\
\text { retoque }\end{array}$ & 75 & 106 & 1,44 \\
\hline Raspador & 1 & 1 & 1,00 \\
\hline $\begin{array}{l}\text { Lámina retoque } \\
\text { lateral }\end{array}$ & 24 & 36 & 1,41 \\
\hline Muesca & 3 & 5 & 1,60 \\
\hline Truncadura & 1 & 1 & 1,00 \\
\hline Buril & 2 & 3 & 1,50 \\
\hline Total & 106 & 152 & \\
\hline
\end{tabular}

\section{LAS ACTIVIDADES DESARROLLADAS}

Mediante el análisis traceológico de este conjunto de láminas hemos podido reconocer una serie de actividades deducidas de las huellas de uso. El objetivo de este apartado es, por lo tanto, valorar de forma sintetizada las tareas que aquellos primeros grupos neolíticos hicieron con tales láminas y poner de relieve ciertos aspectos sobre sus pautas económicas. No obstante, conviene recordar la parcialidad de estas informaciones al abordar exclusivamente instrumentos líticos tallados y en concreto soportes laminares.

El espectro de materias trabajadas, recogidas en la citada figura 6 , muestra un predominio de la manipulación de materias animales, jugando un papel más restringido los trabajos sobre materias vegetales.

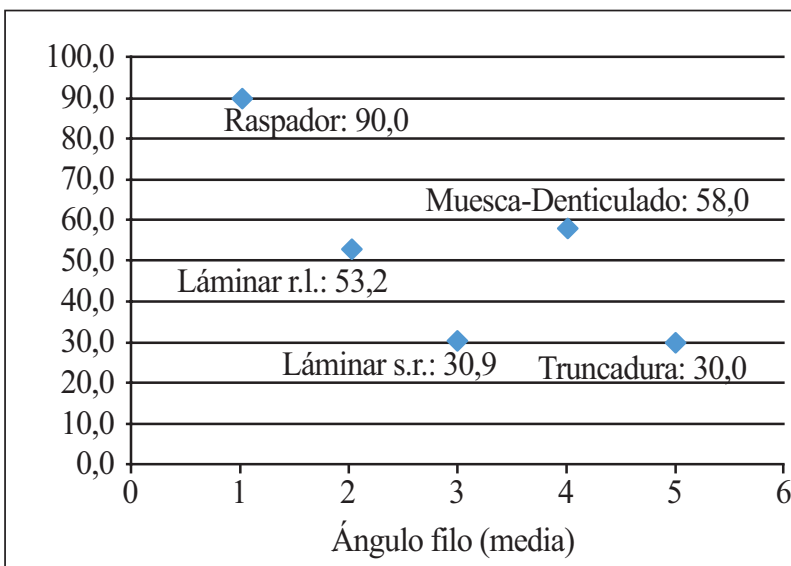

Para los trabajos sobre las materias animales hemos distinguido dos tipos de actividades: por un lado, los trabajos de carnicería y piel fresca, llevados a cabo con láminas sin retocar y vinculados con las primeras fases del procesado de los animales (Philibert 1999; Gassin 1996); y por otro lado, los trabajos sobre piel seca y materias óseas, que suelen asociarse con los procesos de fabricación de otro tipo de adornos, útiles, recipientes, etc. (Calvo et al. 2009). La presencia de ornamentos fabricados sobre materias óseas en los niveles neolíticos de este yacimiento (Pau en prensa) constata este tipo de actividades. Algunas de las láminas con retoque lateral continuo y una de las muescas se emplearon en las primeras fases de obtención/fabricación de instrumentos de hueso; mientras que las pocas tareas de reparación y/o acabado de objetos elaborados en piel seca (en alguna de las láminas, además, (Ref. 612781) se han observado posibles residuos de ocre que pueden vincularse con el tratamiento de las pieles para el curtido, impermeabilización, etc.) se llevaron a cabo con láminas sin retoque.

Paralelamente, debemos pensar que debió ser habitual el empleo de otro tipo de instrumentos. Mientras ciertos cantos y lajas de piedra debieron ser muy efectivos para la configuración de objetos de hueso/asta o madera (Gibaja 2003: 117); otro tipo de utillaje, hoy desaparecido, confeccionado sobre hueso y madera (Bosch et al. 1996, 2011) pudo igualmente servir para el desarrollo de diversas actividades. En definitiva, mientras los procesos más bastos de fabricación pudieron desarrollarse con otro tipo de utensilios, las fases de acabado o mantenimiento pudieron llevarse a cabo con láminas de sílex ligeramente retocadas, como las aquí estudiadas.

En lo que respecta a la manipulación de materias vegetales, también pueden distinguirse dos tipos de

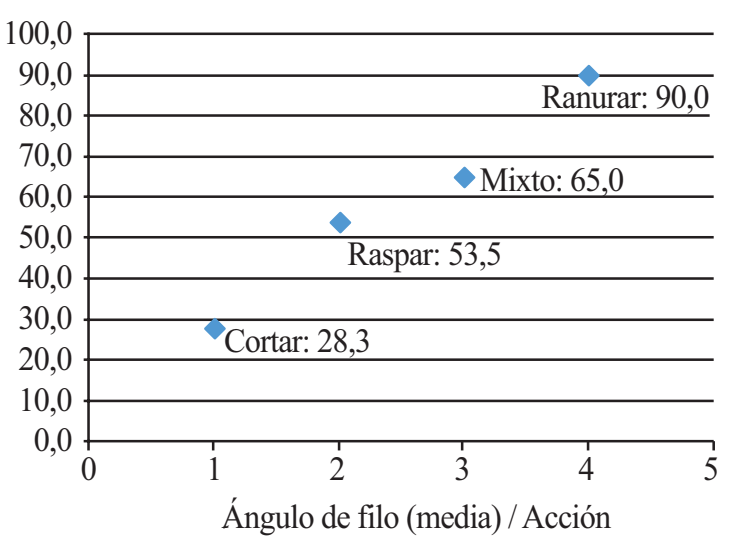

Figura 10. Ángulos de filo en relación al tipo de útil y a la acción realizada. 


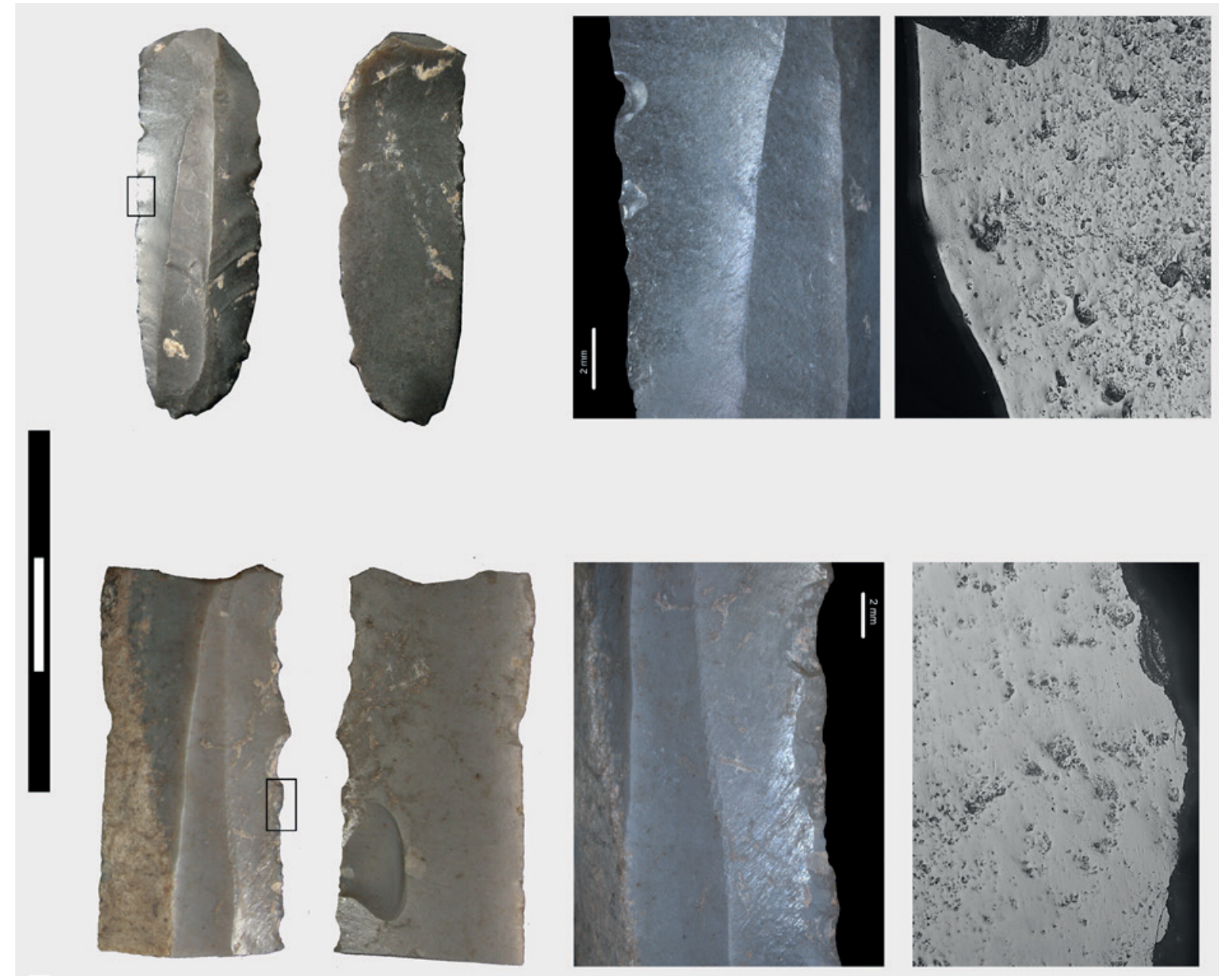

Figura 11. Láminas destinadas al corte de cereales. El enmangamiento fue realizado en diagonal a modo de pequeños dientes. Las fotos microscópicas están a 100X.

actividades. Por un lado, hay un conjunto de láminas con huellas de madera y vegetales indeterminados no leñosos, que debieron haberse destinado a actividades de fabricación y/o reparación de objetos, como por ejemplo, vástagos de flechas, mangos, recipientes/objetos de cestería, etc. Estas tareas exigen acciones de raspado e incluso de ranurado, como las documentadas normalmente entre los útiles (generalmente los retocados) de nuestro estudio.

Por otro lado, hemos identificado tres elementos de hoz empleados en las actividades agrícolas practicadas por las comunidades neolíticas asentadas en Los Castillejos de Montefrío. Evidencias del uso de instrumentos de corte en la cosecha de cereales ya fueron constatadas cuando se analizaron los restos vegetales procedentes del yacimiento (Rovira 2007). Tales elementos destacan por sus implicaciones económicas, asociadas a las nuevas formas de vida neolítica, pero llama la atención el escaso peso cuantitativo de estos elementos en el utillaje lítico. En este caso, se trata de tres fragmentos de lámina, dos de los cuales presentan los filos laterales retocados producto de su reavivado. La escasez de estrías responde a que la siega realizada fue alta, sin contacto con las partículas de tierra habitualmente adheridas a las partes basales de los tallos (fig. 11).

Diversos estudios traceológicos llevados a cabo en las dos últimas décadas sobre este tipo de elementos (Anderson 1993; Ibáñez et al. 2008; Palomo et al. 2011) han demostrado que a partir de la distribución del pulido de cereal puede deducirse la posición de las láminas en los mangos. En el caso de las hoces de Castillejos dicha distribución nos ha indicado que se enmangaron varias láminas en diagonal a modo de dientes.

Este tipo de hoces se han documentado fundamentalmente en contextos del Neolítico Antiguo del centro 
y la parte meridional de la Península Ibérica. Los ejemplos más cercanos los encontramos en yacimientos andaluces como Murciélagos de Zuheros, Murciélagos de Albuñol, Cabecicos Negros, Cueva del Toro, Nerja y Bajondillo; en el área levantina (Mas d'Is, Cova de l'Or y Sarsa) y en la Estremadura portuguesa (Cortiçois) (Gibaja et al. 2010b, 2012; Carvalho et al. 2013).

Por el contrario, en el noreste e interior peninsular, así como en el sudeste francés, las láminas y ocasionalmente las lascas fueron insertadas en paralelo en los mangos de las hoces o se usó una única lámina grande enmangada en diagonal. El mejor ejemplo lo tenemos en una de las hoces de la Draga que aún conserva la lámina de sílex insertada (Gibaja et al. 2007; Gassin et al. 2008; Palomo et al. 2011; Gibaja et al. 2012).

\section{CONCLUSIONES}

El análisis traceológico que hemos realizado sobre el utillaje laminar de Castillejos de Montefrío nos ha permitido conocer el comportamiento funcional de una de las industrias básicas del Neolítico Antiguo, aportando, además, información sobre una parte de las actividades llevadas a cabo en este yacimiento.

Los datos obtenidos evidencian el intenso uso de las láminas aprovechando la efectividad de sus filos naturales. En ocasiones estos se modifican mediante retoques simples o semiabruptos con el objetivo de reavivarlos, reforzarlos o configurarlos de una manera determinada. Es entonces cuando los hemos clasificado tipológicamente -según la disposición y tipo de retoque- como láminas de retoque lateral continuo, truncaduras o muescas. En efecto, a menudo el retoque modifica levemente la forma del filo buscando ciertos rasgos y potenciando su efectividad. Así por ejemplo, la modificación del ángulo del filo aumenta su resistencia para acometer con mayor éxito el trabajo de materias duras/abrasivas o reafilándolo para prolongar su vida útil. Esta idea se refuerza si tenemos en cuenta que entre estas piezas retocadas también ha sido frecuente el uso de otras zonas activas naturales. Por ello, resaltamos la importancia de este tipo de utillaje sin retocar, identificado a partir de los estudios traceológicos, y la necesidad de tener en cuenta este tipo de datos a la hora de entender y caracterizar el utillaje lítico tallado de las sociedades prehistóricas. De hecho, los datos se completan significativamente al incluir estas piezas dentro del utillaje lítico, ampliando la visión sobre los artefactos líticos empleados por estas comunidades.
No podemos descartar además que el retoque se realizara tras un uso previo de los filos naturales de estas láminas. La dificultad en estos casos reside en la identificación de las huellas de utilización vinculadas con las diversas tareas efectuadas con un mismo filo, más cuando gran parte de las huellas han desaparecido con las extracciones producidas por el retoque. Por todo ello, pensamos que en muchos casos el retoque puede interpretarse en términos de reciclaje, reavivado o acondicionamiento (inicial o no) de las zonas activas, como se ha propuesto en otros yacimientos neolíticos (Gibaja et al. 2010a; Gassin 1999).

Paralelamente, la diversidad de materias trabajadas nos ha demostrado la polifuncionalidad inherente a este tipo de utillaje -muy evidente en el caso de las láminas sin retoque-, al igual que ocurre en otros contextos del Neolítico (Rodríguez 2004; Gibaja et al. 2010a; Alday et al. 2012). Además, el índice de utilización, evaluado por el número de zonas activas usadas en cada lámina, ha evidenciado el alto grado de aprovechamiento de estos utensilios. Todas las características subrayadas anteriormente explican por qué estos instrumentos pasan a convertirse en una de las principales herramientas para el desarrollo de las distintas actividades llevadas a cabo en Castillejos durante los primeros episodios neolíticos.

Finalmente, los resultados obtenidos nos han permitido arrojar luz sobre ciertos aspectos de la utilización del asentamiento por parte de sus habitantes durante los episodios señalados. A este respecto, cabe resaltar que hemos documentado trabajos de procesado y consumo de la fauna y, en menor medida, de los cereales, así como tareas ligadas a la fabricación y/o mantenimiento del utillaje realizado sobre materias orgánicas (animales y vegetales).

La representatividad de las actividades reflejadas en los instrumentos líticos tallados coincide con la observada en otros contextos de inicios del neolítico de Andalucía como la Cueva del Toro y Murciélagos de Zuheros (Rodríguez 2004, Carvalho et al. 2013). Al igual que en Castillejos de Montefrío, en tales yacimientos, sobresalen los instrumentos destinados al procesado de materias animales blandas (especialmente carne y piel), siendo muy minoritario el papel de los útiles empleados en la siega de los cereales. Este desequilibrio, pensamos, debe estar relacionado con la propia funcionalidad de los asentamientos más que con la importancia de la agricultura en los sistemas económicos de estas comunidades. El desarrollo de nuevos estudios traceológicos más profundos, en combinación con otras analíticas, será fundamental para tratar de esclarecer este tipo de cuestiones. 
Asimismo, suelen ser muy escasos los elementos de proyectil (microlitos geométricos) dedicados a acciones cinegéticas. Aunque es posible que otros instrumentos o técnicas pudieran emplearse tanto para la recogida del cereal como para la elaboración de las puntas de proyectil, sorprende su ausencia cuando se trata de útiles altamente representados, por ejemplo, en yacimientos neolíticos del este peninsular de Valencia y Cataluña.

Puede, por tanto, concluirse que la producción del utillaje laminar fue básica para el desarrollo de sus estrategias de subsistencia en aquellas primeras comunidades de agricultores y pastores que ocuparon el sur peninsular durante los primeros momentos del Neolítico. Somos conscientes de que se trata de un trabajo preliminar y esperamos que los resultados aquí expuestos sirvan en un futuro, conjugándose con los aportados por otras disciplinas, para entender de forma más completa el yacimiento y el papel que éste pudo jugar en el proceso de neolitización de esta región. En todo caso contribuye a engrosar los trabajos que sobre la función del utillaje lítico tallado se han ido desarrollando en los últimos años para esta área geográfica (Gibaja et al. 2010c).

\section{Agradecimientos}

El análisis traceológico presentado se ha realizado en el marco del proyecto ERC: AGRIWESTMED "Origins and spread of agriculture in the western Mediterranean region" (ERC-AdG-230561). Queremos agradecer desde estas líneas los comentarios realizados por los dos revisores de este trabajo. Sin duda sus aportaciones han mejorado mucho las cuestiones que hemos planteado.

\section{BIBLIOGRAFÍA}

Afonso, J.A. (1993): Aspectos técnicos de la producción lítica de la Alta Andalucía y el Sureste. Tesis Doctoral, Universidad de Granada. Inédita.

Aguilera, M.; Araus, J.L.; Voltas, J.; Rodríguez, Ma.O.; Molina, F.; Rovira, N.; Buxó, R. y Ferrio, J.P. (2008): "Stable carbon and nitrogen isotopes and quality traits of fossil cereal grains provide clues on sustainability at the beginnings of Mediterranean agriculture". Rapid Communications in Mass Spectometry 22: 1653-1663. DOI: 10.1002/rcm.3501

Alday Ruiz, A. y Moral Del Hoyo, S. (2011): "El dominio de la cerámica boquique: discusiones técnicas y cronoculturales", en J. Bernabeu, A. Rojo y L. Molina (coords.), Las primeras producciones cerámicas: El VI Milenio Cal AC en la Península Ibérica. Sagvntvm. Papeles del Laboratorio de Arqueología de Valencia Extra-12: 65-80.

Alday, A.; Castaños, P. y Perales, U. (2012): “Quand ils ne vivaient seulement de la chasse: preuves de domestication ancienne dans les gisements néolitiques d'Atxoste et de Mendandia (Pays Basque)". L'Anthropologie 116: 127-147. doi:10.1016/j.anthro.2012.03.007.

Anderson, P.; Beyries, S.; Otte, M. y Plisson, H. (eds.) (1993): Traces et Fonction: les gestes retrouvés. Colloque international de Liége. ERAUL 50. Lieja.

Arribas, A. y Molina, F. (1979a): El poblado de "Los Castillejos" en Las Peñas de los Gitanos (Montefrío, Granada). Campaña de excavaciones de 1971. El corte número 1. Cuadernos de Prehistoria de la Universidad de Granada. Serie Monográfica 3. Granada.

Arribas, A. y Molina, F. (1979b): "Nuevas aportaciones al inicio de la metalurgia en la Península Ibérica. El poblado de Los Castillejos de Montefrío, (Granada)", en M. Ryan (ed.), Proceedings of the fifth Atlantic Colloquium: 7-34. Stationery Office, Dublín.

Bernabeu, J.; Molina, L.; Díez, A. y Orozco, T. (2006): "Inequalities and Power. Three millennia of Prehistory in Mediterranean Spain (5600-2000 cal BC)", en P. Díaz del Río y L. García Sanjuán (eds.), Social Inequality in Iberian Late Prehistory. Papers from the session "Social Inequality in Iberian Late Prehistory" Faro (2004). British Archaeological Reports. International Series 1525: 97-116. Oxford.

Bernabeu, J.; Molina, L.; Esquembre, M.A.; Ramón, J. y Boronat, J.D. (2009): "La cerámica impresa mediterránea en el origen del Neolítico de la Península Ibérica", en De Méditerranée et d'ailleurs... Mélanges offerts à Jean Guilaine. Archives d'Écologie Préhistorique: 463-478. Toulouse.

Bosch, A.; Chinchilla, J.; Piqué, R. y Tarrús, J. (1996): "Hallazgo de los primeros utensilios de madera en el poblado neolítico de La Draga (Banyoles, Girona)". Trabajos de Prehistoria 53: 147-154.

Bosch, A.; Chinchilla, J. y Tarrús, J. (coords.) (2011): El poblat lacustre del Neolitic antic de La Draga. Excavacions 2000-2005. Monografies del CASC. Barcelona.

Calvo, M.; Ibáñez, J.J. y González, J.E. (2009): “Análisis funcionales de las industrias líticas del Tardiglaciar en el área pirenaico-cantábrica”, en XIV Col. 
loqui internacional d'arqueologia de Puigcerdá. Els Pirineus $i$ les arees circumdantes durant el Tardiglacial: 239-281. Puigcerdá.

Cámara Serrano, J.A., Molina González, F. y Afonso Marrero, J.A. (2005): "La cronología absoluta de Los Castillejos en Las Peñas de los Gitanos (Montefrío, Granada)", en P. Arias, R. Ontañón y C. García-Moncó (eds.), Actas del III Congreso del Neolítico en la Península Ibérica. Monografías del Instituto Internacional de Investigaciones Prehistóricas de Cantabria 1: 841-852. Santander, Universidad de Cantabria.

Carvalho, A.F.; Gibaja, J.F. y Gavilán, B. (2012): "Technologie, typologie et analyses fonctionnelles de l'outillage lithique durant le Néolithique Ancien dans la Cueva de Murciélagos de Zuheros (Córdoba, Espagne): réflexions sur la néolithisation du sud de la Péninsule Ibérique". L’Anthropologie 116: 148170. http://dx.doi.org/10.1016/j.anthro.2012.02.001

Carvalho, A.F.; Gibaja, J.F. y Cardoso, J.L. (2013): “Insights into the earliest agriculture of Central Portugal: sickle implements from the Early Neolithic site of Cortiçóis (Santarém)". Comptes Rendus Palevol 12: 31-43. doi:10.1016/j.crpv.2012.09.004

Cortés Sánchez, M.; Jiménez Espejo, F.J.; Simón Vallejo, M.D.; Gibaja Bao, J.F.; Carvalho, A.F.; Martínez Ruiz, F.; Rodrigo Gámiz, M.; Flores, J.A.; Paytan, A.; López Sáez, J.A.; Peña Chocarro, L.; Carrión, J.S.; Morales, A.; Roselló, E.; Riquelme, J.A.; Dean, R.M.; Salgueiro, E.; Martínez, R.M.; Rubia de Gracia, J.J. de la; Lozano-Francisco, M.C.; Vera-Peláez, J.L.; Llorente, L. y Bicho, N.F. (2012): "The Mesolithic-Neolithic transition in southern Iberia". Quaternary Research 77(2): 221234. doi:10.1016/j.yqres.2011.12.003

Díez, A.; Bernabeu, J.; Orozco, T. y La Roca, N. (2010): "Las campañas de excavación de 2010 y 2011 en el Mas d'Is (Penàguila, Alacant)". Sagvntvm. Papeles del Laboratorio de Arqueología de Valencia 42: 105-109.

Domanski, M. y Webb, J. (2007): “A review of heat treatment research”. Lithic Technology 32(2): 153-194.

Esquembre, M.A.; Boronat, J.D.; Jover, F.J.; Molina, F.J.; Luján, A.; López, J.; Martínez, R.; Iborra, P.; Ferrer, C.; Ruiz, R. y Ortega, J.R. (2008): "El yacimiento neolítico del Barranquet (Oliva)", en M.S. Hernández, J.A. Soler y J.A. López (eds.), IV Congreso del Neolítico Peninsular: 217-230. MARQ. Museo Arqueológico de Alicante (2006). Alicante.

Fernández, J.; Márquez, J.E. y Crespo, M. (2006): “El Charcón: un yacimiento neolítico al aire libre con cerámica cardial en Alozaina (Málaga - España)", en N. Bicho y H. Verissimo (eds.), Do Epipaleolitico ao Calcolítico na Península Ibérica. Actas del IV Congreso de Arqueologia Peninsular Promontoria Monográfica 4: 135-143. Universidade do Algarve (2004). Faro.

García-Puchol, O.; Díez, A.; Bernabeu, J. y La Roca, N. (2008): "El yacimiento prehistórico de Regadiuet (Alcoi, Alacant): Datos preliminares de la secuencia mesolítica y neolítica”, en M.S. Hernández, J.A. Soler y J.A. López (eds.), IV Congreso del Neolítico Peninsular: 70-78. MARQ, Museo Arqueológico de Alicante (2006). Alicante.

Gassin, B. (1996): Évolution socio-économique dans le Chasséen de la grotte de l'Église supérieure (Var). Apport de l'analyse fonctionelle des industries lithiques. París, Éditions du CNRS, 17.

Gassin, B., (1999): "La structure fonctionnelle des industries lithiques du complexe chasséen en Provence", en XXIV Congrès préhistorique de France, Le Néolithique du Nord-Ouest méditerranéen: 119128. Carcassonne, (1994). Carcassonne.

Gassin, B.; Bicho, N. F.; Bouby, L.; Buxó, R.; Carvalho, A. F., Clemente, I., Gibaja, J. F., et al. (2008): "Variabilité des techniques de récolte et traitement des céréales dans l'occident méditerranéen au Néolithique ancien et moyen: facteurs environnementaux, économiques et sociaux", en Actes des 7émes Rencontres Méridionales de Préhistoire Récente: 1-23. Lyon - Bron (2006). Lyon-Bron.

Gibaja, J.F. (2003): Comunidades neolíticas del Noreste de la Península Ibérica. Una aproximación socio-económica a partir del estudio de la función de los útiles líticos. BAR International Series $S 1140$. Oxford.

Gibaja, J.F.; Terradas, X. y Palomo, A. (2007): “El Neolítico del Noreste de la Península Ibérica: caracterización del utillaje lítico tallado". Promontoria 5: 163-184.

Gibaja, J.F.; Cortés, M. y Simón, M.D. (2010a): “La función del utillaje lítico neolítico: el ejemplo de la cueva de Nerja (Málaga)". Spal 19: 97-110. http:// dx.doi.org/10.12795/spal.2010.i19.04

Gibaja, J.F.; Ibáñez, J.J. y Cabanilles, J.J. (2010b): "Análisis funcional de piezas con lustre neolíticas de la Cova de l'Or (Beniarrés, Alicante) y la Cova de la Sarsa (Bocairent, Valencia)". Archivo de Prehistoria Levantina 28: 91-106.

Gibaja, J.F.; Ibáñez, J.J.; Rodríguez, A.; González, J.E.; Clemente, I.; García,V. y Perales, U. (2010c): "Estado de la cuestión sobre los estudios traceológicos 
realizados en contextos mesolíticos y neolíticos del sur peninsular y noroeste de África". Promontoria 15: $181-190$.

Gibaja, J.F., Estremera, M.S., Ibáñez, J.J. y Perales, U. (2012): "Instrumentos líticos tallados del asentamiento neolítico de la Vaquera (Segovia) empleados en actividades agrícolas". Zephyrus LXX: 33-47.

González, J.E. e Ibáñez, J.J. (1994): Metodología de análisis funcional de instrumentos tallados en sílex. Bilbao, Universidad de Deusto.

González, J.E.; Ibáñez, J.J.; Peña, L.; Gavilán, B.; Carlos, J. y Vera, J.C. (2000): "El aprovechamiento de los recursos vegetales en los niveles neolíticos del yacimiento de los Murciélagos (Zuheros, Córdoba). Estudio arqueobotánico y de la función del utillaje". Complutum 11: 171-189.

Ibáñez, J.J.; Clemente. I.; Gassin, B.; Gibaja, J.; González, J.E.; Márquez, B.; Philibert, S. y Rodríguez, A. (2008): "Harvesting technology during the Neolithic in South-West Europe", en L. Longo y N. Sakakun (eds.), Prehistoric Technology 40 years later. BAR International Series 1783: 183-195. Oxford.

Leisner, G. y Leisner, V. (1943): Die Megalithgräber der Iberischen Halbinsel. Der Süden. RömischGermanische Forschungen 17. Berlín.

Martínez, G. (1985): Análisis tecnológico y tipológico de las industrias de piedra tallada del Neolítico, la Edad del Cobre y la Edad del Bronce de la Alta Andalucía y del Sudeste. Tesis Doctoral, Universidad de Granada. Inédita.

Martínez, G.; Morgado, A.; Afonso, J.A.; Cámara, J.A. y Cultrone, G. (2006): "Explotación de rocas silíceas y producción lítica especializada en el subbético central granadino (IV-III Milenios cal. B.C.)", en G. Martínez, A. Morgado y J.A. Afonso (coords.), Sociedades prehistóricas, recursos abióticos y territorio. Actas de la III Reunión de trabajo sobre aprovisionamiento de recursos abióticos en la Prehistoria: 293-313. Fundación Ibn al-Jatib/ Ayuntamiento de Loja, Granada (2006). Granada.

Martínez, G. y Afonso, J.A. (2008): “L'évolution morpho-technique des artefacts taillés au tours de IVéme -III ème millénaires B.C. au Sud de la Péninsule Ibérique", en M.H. Dias-Meirinho, V. Lea, K. Gernigon, P. Fouéré, F. Briois y M. Bailly (eds.), Les industries lithiques taillées des IV - III millénaires en Europe occidentale. British Archaeological Reports. International Series 1884: 291-308. Oxford.

Martínez, G.; Afonso, J.A.; Cámara, J.A. y Molina, F. (2009): "Desarrollo histórico de la producción de hojas de sílex en Andalucía oriental", en J.F.
Gibaja, X. Terradas, A. Palomo y X. Clop (coords.), Les grans fulles de sílex. Europa al final de la prehistòria. Actes, Monografies 13: 15-24. Museu d'Arqueologia de Catalunya, Ajuntament de Gavà, (2009). Barcelona.

Martínez, G.; Afonso, J.A.; Cámara, J.A. y Molina F. (2010): “Contextualización cronológica y análisis tecnotipológico de los artefactos tallados del Neolítico antiguo de Los Castillejos (Montefrío, Granada)", en J.F. Gibaja y A.F. Carvalho (eds), Os últimos caçadores-recolectores e as primeiras comunidades produtoras do sul da Península Ibérica e do norte de Marrocos. Promontoria Monográfica 15: 163-171. Faro, Universidade do Algarve.

McCutcheon, P.T. y Kuehner, S.M. (1997): "From macroscopic to microscopic: understanding prehistoric heat treatment of Stone tools", en A. Ramos y M A. Bustillo (eds.), Siliceous rocks and culture, Monográfica Arte y Arqueología 42: 447-462. Granada, Universidad de Granada.

Mergelina, C. de (1941-1942): “La estación arqueológica de Montefrío (Granada) I. Los dólmenes". Boletín del Seminario de Arte y Arqueología VIII: 33-106.

Morgado, A.; Martínez, G.; Martín, J. y Roncal, M E. (2001): "Prospección arqueológica en relación con la explotación prehistórica de rocas silíceas en el sector occidental de la región de "Los Montes" (Granada). Avance preliminar". Anuario Arqueológico de Andalucía 1997, vol. II: 77-85.

Nachasova, I.E.; Burakov, K.S.; Molina, F. y Cámara, J.A. (2007): "Archaeomagnetic Study of Ceramics from the Neolithic Los Castillejos Multilayer Monument (Montefrío, Spain)". Izvestiya. Physics of the Solid Earth 43(2): 170-176.

Palomo, A.; Gibaja, J. F.; Pique, R. y Bosch, A. (2011): "Harvesting cereals and other plants in Neolithic Iberia: the assemblage from the lake settlement at La Draga". Antiquity 85: 759-771. http://antiquity. ac.uk/ant/085/ant0850759.htm.

Pau, C. (2011a): "Estudio morfológico, morfométrico y traceológico de los adornos en concha del poblado de los Castillejos en Las Peñas de los Gitanos", en M. Sánchez (ed.), Memorial Luis Siret. Primer Congreso de Prehistoria de Andalucía. La tutela del patrimonio prehistórico: 563-566. Antequera (2010). Antequera, Consejería de Cultura de la Junta de Andalucía.

Pau, C. (en prensa): "Los ornamentos en materia ósea del neolítico en el poblado de Los Castillejos de Montefrío", en V.S. Gonçalves, M. Diniz y A.C. Sousa (coords.), $5^{\circ}$ Congresso do Neolítico Peninsular 20. 
Uniarq. Centro de Arqueologia da Universidade de Lisboa. Lisboa.

Philibert, S. (1999): "Modalités d'occupation des habitats et territoires mésolithiques par l'analyse tracéologique des industries lithiques: l'example de quatre sites saisonniers", en L'Europe des derniers chasseurs, 5, Colloque international UISPP: $145-$ 155. Warsaw and Ostrowiec (1995). Warsaw and Ostrowiec.

Ramos, J. y Lazarich, M. (2002): Memoria de la excavación arqueológica en el asentamiento del $\mathrm{VI}^{\circ} \mathrm{Mi}$ lenio A.N.E. de "El Retamar" (Puerto Real, Cádiz). Arqueología Monografías 3. Sevilla, Consejería de Cultura de la Junta de Andalucía.

Riquelme Cantal, J.A. (1996): Contribución al estudio arqueofaunístico durante el Neolítico y la Edad del Cobre en las Cordilleras Béticas: el yacimiento arqueológico de Los Castillejos en Las Peñas de los Gitanos, Montefrio (Granada). Tesis Doctoral, Universidad de Granada. Inédita.

Rodríguez, A. (2004): “Análisis funcional de los instrumentos líticos tallados", en D. Martín (ed.), La Cueva de El Toro (Sierra de El Torcal, AntequeraMálaga). Un modelo de ocupación ganadera en territorio andaluz: entre el VI y II milenios A.N.E. Arqueología Monografías. Sevilla, Junta de Andalucía, Consejería de Cultura.

Rovira i Buendia, N. (2007): Agricultura y gestión de los recursos vegetales en el sureste de la Península Ibérica durante la Prehistoria Reciente. Tesis Doctoral, Universitat Pompeu Fabra, Barcelona. Inédita.

Sánchez Romero, M. (2000): Espacios de producción y uso de los útiles de piedra tallada del Neolítico. El poblado de "Los Castillejos de Las Peñas de Los Gitanos" (Granada, España). British
Archaeological Reports. International Series 874. Oxford.

Tarradell i Mateu, M. (1952): "La Edad del Bronce en Montefrío (Granada). Resultados de las excavaciones en yacimientos de Las Peñas de los Gitanos". Ampurias 14: 49-80.

Torregrosa, P.; Jover, F.J. y López, E. (2011): Benàmer (Muro d'Alcoi, Alicante). Mesoliticos y neolíticos en las tierras meridionales valencianas. Servicio de Investigación Prehistórica del Museo de Prehistoria de Valencia. Serie de Trabajos Varios 112. Valencia, Diputación de Valencia.

Uerpmann, H.P. (1979): "Informe sobre los restos faunísticos del corte $n 1$ 1. El poblado de Los Castillejos en Las Peñas de Los Gitanos (Montefrío, Granada). Campaña de excavaciones de 1971. El corte número 1". Cuadernos de Prehistoria de la Universidad de Granada. Serie Monográfica 3: 153-168.

Vijande, E. (2009): "El poblado de Campo de Hockey (San Fernando, Cádiz): resultados preliminares y líneas de investigación futuras para el conocimiento de las formaciones sociales tribales en la Bahía de Cádiz (tránsito V-IV milenios a.n.e.)". Revista Atlántica-Mediterránea de Prehistoria y Arqueología Social 11: 265-284.

Yanes, Y.; Romanek, C.S.; Molina, F.; Cámara, J.A. y Delgado, A. (2011): "Holocene Paleoenvironment ( 7200-4000 cal BP) of the Los Castillejos Archaeological site (SE Spain) inferred from the stable isotopes of land snail shells". Quaternary International 244: 67-75. http://dx.doi.org/10.1016/j. quaint.2011.04.031

Ziegler, R. (1990): “Tierreste aus der Prähistorischen siedlung von Los Castillejos bei Montefrío (Prov. Granada)". Studien über frühe Tierknochenfunde von der Iberischen Halbinsel 12: 1-47. 